\title{
Emergent subjectivity in caring institutions for teenagers
}

\author{
Susanne Severinsson and Catharina Nord
}

\section{Linköping University Post Print}

\section{Tweet}

N.B.: When citing this work, cite the original article.

This is an electronic version of an article published in:

Susanne Severinsson and Catharina Nord, Emergent subjectivity in caring institutions for teenagers, 2015, Pastoral Care in Education, (33), 3, 137-146.

Pastoral Care in Education is available online at informaworld ${ }^{\mathrm{TM}}$ :

http://dx.doi.org/10.1080/02643944.2015.1049647

Copyright: Taylor \& Francis (Routledge): SSH Titles / Wiley

http://www.routledge.com/

Postprint available at: Linköping University Electronic Press

http://urn.kb.se/resolve?urn=urn:nbn:se:liu:diva-117638 


\title{
Emergent subjectivity in caring institutions for teenagers
}

\author{
Susanne Severinsson \& Catharina Nord \\ Department of Social and Welfare Studies, Linköping University, Norrköping, Sweden.
}

\begin{abstract}
We investigate how different mealtime situations help shape teenager and staff subjectivities in two Swedish residential care homes and a special school for girls and boys, 12-15 years old, with social, emotional, and behavioural difficulties. Three mealtime networks are analysed using concepts from actor-network theory, treating architectural space and artefacts, as well as teenagers and staff, as actors. The architectural spaces in the kitchen and dining room were first created for other purposes than residential care for troubled youth (i.e. a former farm, hospital, and preschool) and have been adapted to be more homelike while coping with housing and feeding 20 or more people. The original architectural spaces as well as activities before mealtimes were powerful actors in the mealtime network, causing different subjectivities to emerge in the translations. The subjectivities emerge in the first network as offenders/guards, in the second network as small children/nannies, and in the third network as guests/service staff. The different translations in the three meal networks create different mobilization opportunities for the teenagers concerning responsibility and normality.
\end{abstract} Keywords: residential care, actor-network theory, mealtime, SEBD 


\section{Introduction}

Residential care homes are a therapeutic and educational resource for young individuals who cannot be handled by ordinary schools because of their social, emotional, and behavioural difficulties (SEBD). ${ }^{1}$ In Sweden, these homes are called 'homes for care or residency', abbreviated to HVB. ${ }^{2}$ HVBs are institutions with the therapeutic aim of helping teenagers become functional individuals (Winzer, 2005). The teenagers in HVBs are often assessed as aggressive, self-destructive, violent, or criminal. However, it must be stressed that these negative attributions arise from situations of extreme vulnerability in which the teenagers express 'despair, abandonment, helplessness and lack of control over their lives’ (Wright, 2009, p. 282). They leave their ordinary homes for treatment in HVBs for periods lasting a few months up to one or two years, visiting their families on weekends if possible. HVBs are often located in rural areas. The removal of the teenagers from their ordinary homes is intended to have a positive impact on these troubled individuals by disrupting adverse habits and replacing them with more appropriate ones. The overall aim of HVBs is to nurture the teenagers back to a normal life. The goal is for the teenagers to return to their ordinary homes, even though these homes might be dysfunctional in some respects (Susanne Severinsson, 2010). Place thus figures significantly in interpreting the teenagers' situations and the intervention. While place is regarded as a disruptive factor in the parental home context, it is used to further the teenagers' progress in the HVB.

\section{Ambiguous interventions}

Interventions in HVBs are situated in the intersection between social care, treatment, and teaching (S Severinsson, Nordh, \& Reimers, 2014). This implies that HVBs simultaneously apply the contradictory discourses of punishment and social welfare, blurring blame and discipline with care and sympathy. These divergent discourses contribute to highly ambiguous environments in which the three discursive practices of social care, treatment, and teaching occur simultaneously or alternately. Architecture and artefacts often contribute substantially to this ambiguity by creating environments in which institutional and family like elements are mixed (Susanne Severinsson, Nord, \& Reimers, 2014). Family life or family-likeness is sometimes a significant ideological benchmark when such interventions are implemented

\footnotetext{
${ }^{1}$ The term 'social, emotional, and behavioural difficulties' (SEBD) is used in the UK, while in the USA the equivalent term is 'emotional and behavioral difficulties' (EBD). Similar designations are used in most countries.

${ }^{2}$ Hem för Vård eller Boende (HVB) in Swedish.
} 
(Dorrer, McIntosh, Punch, \& Emond, 2010). Certain practices including material components may seek to replicate family life (Kendrick, 2013). Mealtimes in HVBs are important events as part of doing family life, often enacted as fellowship around a kitchen table (Kohli, Connolly, \& Warman, 2010). However, family life is not an entirely clear-cut practice in the context of residential care, because home, institution, and workplace intersect and might therefore not appear as envisioned by staff in the eyes of the resident teenagers (Dorrer et al., 2010). A point of departure for this study is that teenagers (and all other actors too) might understand the mealtime situation in various ways and act according to these translations. We accordingly investigate how various mealtime situations help shape the subjectivity of teenagers in HVBs. The pedagogical and caring dimensions of mealtimes are often perceived by staff as opportunities to shape teenagers in certain ways in accordance with the wider goal of HVB interventions. Our prime interest concerns architecture and artefacts as part and parcel of a formative care model, for achieving pedagogical and caring aims.

\section{Actor-network theory and teenager subjectivity}

According to actor-network theory (ANT), subjectivity emerges in networks in which various actors interact (Callon, 1986; Latour, 2005). These actors can be people, as well as artefacts and material of various kinds. We regard subjectivity as relational, i.e. as resulting from interplay between interconnected actors in networks in which space is significant (Wylie, 2010). Networks and spaces are generated together and 'networks gather diverse space-times' (Murdoch 1998, p. 361) into ‘centred subjectivity’ (Law, 1996, p. 296). However, subjects are not predefined categories with stable qualities. On the contrary, 'nothing pertains to a subject which has not been given to it' (Latour, 2005, p. 213). The teenagers in the HVBs we studied are ascribed subjectivities by the staff, spaces, discourses, and artefacts with which they interact, but they also have opportunities to refuse to accept or act according to these produced subjectivities.

We especially considered architectural space and material as actors and co-producers of subjectivities in mealtime networks. Material such as ceilings and doors is tangible, solid, and artefactual, though it can also be redefined to various extents. 'These materials come into the network with their own space-time trajectories' (Murdoch, 1998, p. 361) and are modified through new interrelationships within the network (Murdoch, 1998). Architectural spaces have the capacity to act in networks to mediate power by means of built form (Dovey, 2008), which is of special importance in HVBs where teenagers are often subordinate to staff. We also use DeLanda (2006, p. 11) and his concept 'exteriority of relations' to indicate how one network 
can be ‘plugged into’ another (DeLanda, 2006, p. 10).

The analysis was performed using concepts from ANT especially from Callon (1986). We regarded the three HVBs as networks of human and nonhuman actors in which performances were carried out, giving shape and meaning to these performances. Artefacts and architectural space, such as the rooms, furniture, and equipment involved in the mealtimes, were treated as having agency and, in addition to people (primarily teenagers and staff), were included in our analysis. The analysis used the central ANT concept of translation, referring in this case to how actors change when they enter a network, for example, by attaining new subject positions (Callon, 1986; Latour, 2005). Translation occurs via four processes. Problematization identifies a problem, the relevant stakeholders, and the identities of these actors/stakeholders. Interessement refers to the consolidation of the predefined identities of the actors and their places in the network by the introduction of certain stabilizing devices and the elimination of competing actors. In enrolment, negotiations allow alliances to be forged among willing actors. Finally, in mobilization, a full translation is achieved when the actors have accepted their enrolment in the network (Callon, 1986). A full translation is a shared singular understanding spoken with one voice (Murdoch, 1998).

The mealtime situations in the three settings are regarded as translations. Teenagers and staff come together in particular settings comprising architectural space and artefacts that make them change and act in various ways. These actors are translated into something new. The four processes mentioned above more or less successfully lead to complete translations. The establishment of a network may be challenged by betrayals and controversies on the part of the actors involved (Callon, 1986). In the mealtime situations analysed here, actors may create controversies, for example, by refusing enrolment, resulting in different translations being enacted simultaneously or translations being regarding as more or less ‘successfully’ produced.

\section{Methodology}

The analysis was based on data obtained by the first author during a year of doctoral ethnographic fieldwork as a participant observer in three institutions, selected because they represented three ways of organizing education and care. Two HVBs were included: Vallby, where six boys lived, had its own school, while Sandbacken, where 22 boys and girls lived, used a local school. Both HVBs were placed in the countryside, near to a town. The third setting was Myrmarken, itself a special school placed in a town, but near a green park. The main empirical material used here is ethnographic notes and recorded observations. In addition, 33 audio-recorded interviews with staff (17) and teenagers aged 12-15 years (11 boys and five 
girls) were used. The interviewed staff was 6 men and 11 women. They were care workers (8), teachers or preschool teachers (6), graduated social workers (2) and one psychologist (1). The study was approved by the regional ethical board based on ethical considerations such as guaranteed confidentiality and voluntary participation by all participants. The names of the institutions and of the individuals quoted are therefore pseudonyms.

\section{Translations and subjectivities in two HVBs and a special school}

Both the HVBs, Vallby and Sandbacken, and the special school, Myrmarken, had undergone physical reconstruction and/or other material changes to accommodate the education and care models applied. Vallby was formerly a family farm, with several added and reconstructed buildings: a barn was converted into a school, a building was added for the boys' accommodation, and an extension was built for the kitchen. Sandbacken, built in the late nineteenth century, used to be a hospital. It is huge, as these old hospital buildings often are. Corridors on both sides of a huge central staircase contain doors opening onto rows of refurbished rooms. Myrmarken - previously a preschool - comprises a one-storey building with two sections for two smaller groups of students and an outside playground with equipment for small children. Minor changes had been made, mainly to the furnishings.

The problematization by which the managements of the three institutions identified problematic issues and the involved actors aimed to create relationships of trust between the staff and teenagers. Such relationships were assumed to be decisive for successful pedagogical and therapeutic interventions. One interviewed staff member identified improved relationships as a sign of success:

It is obvious from the contacts with us grownups. Some of them who move in have no trust whatsoever and as soon as we adults approach, they close themselves off. By the end of the treatment they don't do that any longer - they might ask our opinions and such things.

Architectural space and artefacts were important elements incorporated into the care model network to enact these good relationships. The architectural design was a device for interessement that enacted relationships with connotations of family life, aiming at consolidating familial teenager and staff roles. The designers had made a huge effort to create an ambiance of 'homelikeness', to reinforce the sense of home and family relationships that the staff wanted to establish with the teenagers, in which the teenagers would emerge as children to parents, for which the staff were surrogates (Susanne Severinsson, 2010) . 
Creating conducive architectural environments had proven difficult because architectural space may not cooperate as the designers expect (Latour \& Yaneva, 2008). In the studied cases, the original architectural designs defied the designers' efforts to ascribe the role of family home to the architectural space. Architectural space was, in this sense, not enrolled in the family home enactments.

The designers encountered various difficulties creating homelikeness in all three settings. Our observations revealed that the additions and extensions in Vallby, the former farm, had unexpectedly eliminated some of the homelikeness of the original farm. The design had accidentally damaged the family ambiance it aimed to create, and an institutional ambiance had taken its place. At Sandbacken, efforts to ameliorate the institutional character had failed, as Sandbacken's massive institutional structure did not accommodate the design efforts to create a more homelike environment. The brightly coloured walls and curtains, the plants and art objects on the deep windowsills intended to 'soften' the interiors, the mixture of homey sofas and kitchen tables in the corridors - together these elements failed to eliminate the institutional character of the facility. Although Myrmarken, the former preschool building, had been subject to a similar child/parental problematization, only minor changes were made, since homelikeness was part of the original preschool discourse, reflected in the architectural design and other artefacts. The devices needed for interessement were already in place. The original design, equipment, and furniture assigned family roles to staff and teenagers, and only some furniture needed to be added to facilitate the teenagers' leisure time. However, the play equipment in the playground and the low garment racks in the halls reflected the building's earlier childcare function for younger children than the teenagers now attending the special school.

In all three settings, the pre-existing architectural structure or materiality interfered with the new design or activities. Architectural space and material devices could not be enrolled in enacting the home and family, but rather engendered contradictions that made the institutions difficult to interpret, creating latitude for multiple interpretations. When the complex care model of somewhat contradictory discursive interventions was enacted in these ambiguous spaces, environments of high complexity and ambiguity appeared (cf. Susanne Severinsson et al., 2014) in all three institutions.

The mealtime situations in the two HVBs and the special school all embraced dimensions of care and education. This double aim is obvious from the following quotation from one staff member: 
'One should show the youths how to behave around a table, how to eat, and that it is enjoyable - a kind of family meal.’

Although the three settings shared this underlying aim, the enrolment of material and architectural actors differed between them and, together with other actors, produced diverse subjectivities among both teenagers and staff.

\section{Vallby dining network: architectural and material failure}

The design and organization of the mealtime situation in Vallby was a spatial ensemble of which the teenagers had prior experience and could easily recognize: the family home kitchen. This type of kitchen is an ordinary everyday family ensemble of enrolled spatial and material components that is taken for granted. Great efforts had been made in Vallby to create a homelike family kitchen. The staff envisioned eating together with the teenagers in a familylike sense of community. However, this vision was somewhat at odds with the kitchen's function, which was to serve meals to over 20 people. It had an ordinary family kitchen fridgefreezer, dishwasher, and cooker, but it was substantially larger than a family kitchen, because it had been reorganized and enlarged to accommodate the many cupboards, tables, and chairs needed to hold over 20 people at mealtimes. In this kitchen network, besides all this materiality enrolled to produce 'kitchen', there were a female cook, a kitchen assistant, a teacher, and the teenagers, all arriving hungry for lunch at noon. However, the translation into a kitchen singularity, articulated with one voice and for one purpose, failed to appear (Murdoch, 1998), because the spatial components, the many people, and the hectic activity as people moved around the space made the translation into a kitchen ambiguous, opening the way for alternative translations important to the teenagers' subjectivities.

Every morning, the boys in Vallby attended school. At noon they ran quickly back from school, reaching the kitchen before the teacher and other staff. On arrival, they did not act as though they were in a family home, sitting down at the table, maybe waiting for a parent to serve food. Instead, they seemed to continue to perform the school discursive practice and brought their previous activity into the kitchen. Today, an ordinary school is a machine for controlling most aspects of the school day, moulding school children's subjectivities (Youdell, 2006). It is a complex spatial control apparatus in which powers and agencies are negotiated, not only in the classroom (Fenwick, 1998) but also in associated spaces, such as the library, schoolyard, and corridors (Shilling \& Cousins, 1990; Thompson, Russell, \& Simmons, 2013). These control mechanisms, with which the boys were acquainted, as well as the spatial ambiguity of the Vallby kitchen made the boys line up as if they were in a school canteen, quarrelling about their 
places in the queue, although they were standing in front of the cooker and not at a serving counter. The kitchen staff may have contributed to the unsuccessful family kitchen enrolment by their efforts to keep some discipline. They made great efforts to calm down the boys and did not allow the teenagers to serve themselves. The kitchen assistant or the cook ladled out the portions directly from the pots and pans on the hob, supervising the procedure with comments such as 'just one sausage each' or 'take the potatoes also'. The boys ate their food very quickly at a large round table where arguments and disputes often continued. The teenagers and kitchen staff agreed on the problematization of the meal arrangement. They shared the same interessement regarding eating/feeding quickly and enrolled each other as poorly behaving students and guards.

Most of the teenagers had already finished eating and left before the teacher and other school staff arrived to join them. The teacher and staff were too late to eat lunch with the teenagers and instead ate in peace after the boys, without trying to make the boys stay and keep them company. Pedagogical lunches are a contested issue, because they mean that the staff never actually have any breaks or their own mealtimes (Dorrer et al., 2010). Perhaps neither the staff nor the boys viewed the mealtime through the lens of the family discourse that the kitchen's material configuration suggested. A family kitchen enrolment seemed to have been counteracted by the performance of a school discourse (i.e. lining up), reinforced by the disciplinary kitchen staff and by the teachers' actions, leading to a lunch for staff on their own. This was made possible by a spatio-material melee that created uncertainty about expected behaviour and opened the way for teenager and staff subjectivities outside the expected family discourse of having lunch together. The network produced the subjectivities offenders and guards rather than those belonging to the family discourse, i.e. children and parents.

\section{Myrmarken dining network: imbalanced mobilization}

Myrmarken special school also had intentions of creating a family-like network, because the school's activities again included care and education. The school benefitted from the spatial qualities of the former preschool and served lunch in the two original separate small kitchens, which both looked like family kitchens in ordinary homes. Little had changed since the school was a preschool and every square inch of the rooms was occupied. There was one cooker, one dishwasher, cupboards, and benches in each kitchen. Kitchen chairs for six or seven people surrounded a table without a cloth. When teachers, the cook, and the five boys sat together, it was impossible to move or leave without disturbing everyone. Perhaps the space was planned for smaller children, so with teenagers around the table the configuration was too crowded. 
From this inherited preschool materiality a preschool practice emerged that had consequences for both teenager and staff subjectivities. These actors were invited to enrol in a preschool network, which the staff actually agreed to, while the teenagers were not fully convinced that they should be problematized as ignorant or immature. The lunches were pedagogically oriented, but at a level suited for children younger than teenagers. The food was passed around the table and everyone took a little bit, not much, from the platters and then everybody ate together. The staff controlled the teenagers' food intake with comments such as 'just one spoonful of jam'. The teachers and the cook talked about the food, its nutritional content and healthfulness, in an educational and somewhat patronizing way. When a teenager once put four spoons of sugar in the tea, the opportunity was taken to point out that this was not good for either the teeth or body weight. The teenagers were encouraged to taste everything, as parents often encourage smaller children to do. The teenagers participated reluctantly in the preschool practice and in being problematized and enrolled as young children with infantile connotations. There was a lot of childish playfulness around the table and the boys were treated and sometimes responded as though they were younger than they really were. The mealtime was also used to talk about personal everyday matters, indicating the care dimension of eating together. The teachers and children often stayed at the table, sometimes through the whole lunch break without going outside, a practice associated with family lunch or preschool meals and not with lunch breaks at school.

The meals produced a pattern that was evident in most activities in Myrmarken, in that the spatial and material remains of the preschool seemed to interfere with the facility's current use. The mobilization that occurred was therefore imbalanced, hampering translation to a special school for children aged 12-15 years. The translation instead reproduced a preschool pedagogical network in which teacher activities recalled the minding of smaller children. The network reproduced teenagers as innocent and ignorant, reducing their subjectivity to the level of smaller children, casting the staff as nannies. Some of the teenagers opposed full enrolment in the school for this reason. One of the boys objected, saying that he found the playground embarrassing because 'we are not toddlers'.

\section{Sandbacken: a complete translation}

Sandbacken, the former hospital that had been refurbished to 'soften' its institutional ambiance, also presented spaces of great ambiguity and alternative translations - i.e. those of a hospital, hostel, and boarding school - to that of an HVB. The mealtimes differed greatly 
from those in Vallby and Myrmarken because there had been no efforts to make the dining facilities look like a family kitchen. The dining room was a large room like a hotel dining room, with many small intimate tables beautifully set with tablecloths and candles or flowers. In the middle of the room was a large table with a tablecloth, and at lunchtime it was covered with salads, newly baked bread, and delicious food of restaurant quality served from beautiful platters and baskets. At a certain time, the door to the dining room was opened and the teenagers were invited in. They arrived alone or two by two, served themselves and sat down and waited until all were gathered. No staff oversaw the serving process and the normal arguing and horseplay among the teenagers was absent. Instead, there was a constant murmur about how good everything looked. The hotel dining room impression was bolstered by the muffled sounds of the dishwasher and the clatter of dishes, which slightly intensified when the kitchen doorway occasionally opened. Now and then during the meal, the kitchen staff appeared in the door in the frilly aprons of hotel waitresses asking whether everything was all right or anything was missing. Everyone then assured them that the meal was delicious or asked what was for dessert.

The meals were considered crucial by the head of this HVB, so dessert was served every day. The aim was to create a positive ambiance around the meal, so people could socialize and the teenagers would feel valued. The institutional aim of the mealtimes was to stimulate eating in the teenagers, because eating disorders were common among them. This problematization of eating was not overtly formulated with the teenagers. If one of them did not want to eat or if someone only took dessert, no fuss was made. The high-quality dining coalesced into a full and unambiguous translation in which the teenagers gladly enrolled themselves, in contrast to the Vallby mealtimes described above, without their perceiving the educational and care intentions embedded in the enactment of the meal. The teenagers ate in peace, talking to each other and to the staff, who sat at different tables. This network allowed the teenagers a shortlived subjectivity as 'hotel guests' in spatially attractive surroundings where they could temporarily exchange the HVB subjectivity of teenagers with SEBD for a more sophisticated one that involved enjoying the food and the company of other 'guests'. The staff also assumed the subjectivity of guests. The contrast between the dining hall and the rest of the HVB represented a necessary and temporary distance, a cutting out of a competing actor. The network of actors, staff, teenagers, and architecture all supported the enrolments of guests and other guests/service staff. The teenagers enacted a joint interessement, eating in a pleasant atmosphere that allowed them to abandon their behavioural problems and emerge as respected 
people, before returning to the more institutional parts of the Sandbacken HVB, which were more associated with treatment and discipline.

\section{Discussion}

We find, as did Punch and McIntosh (2013), that meal times allowed the teenagers with SEBD to extend their boundaries, show feelings, and accept or reject care and relationships. Relationships between staff and teenagers similar to those in families have been identified as important to high-quality residential care, and the family metaphor is often invoked by children in care to indicate good relationships (Dorrer et al., 2010; Kendrick, 2013). However, the architecture and interiors in the kitchens and dining rooms of the studied institutions had originally been created for other problematizations and interessements (Callon, 1986) in previous space-times (Murdoch, 1998) and not especially for residential care for troubled teenagers. The settings were a former farm, hospital, and preschool, but all the buildings and interiors had undergone changes to become more homelike and to cope with housing and feeding a substantial number of people. The Vallby family kitchen appeared as a network of ambiguous relationships in which staff and teenagers did not emerge as parents and children. The previously existing school network remained a powerful actor in the mealtime network in Vallby. The school spatial template and its associated acts were moved from the school in Vallby to the kitchen. The school network was 'plugged into' (DeLanda, 2006, p. 10) the kitchen network, constituting 'a relationship of exteriority' (DeLanda, 2006, p. 11) borne by the teenagers but not followed up by the teachers. The kitchen staff instead enrolled themselves as guards and the teenagers as offenders. The mobilization towards normality was receding in this translation and the opportunity to negotiate the belonging and safety that Kohli et al. (2010) talk about were lost.

In Myrmarken too, the original architectural space strongly affected the meal network, causing struggles in the present with the school's historical layers. The preschool pedagogy embedded in Myrmarken's design was at odds with the teenagers' age. This imbalance made it difficult for the teenagers to become mobilized, because treating their emerging teenager's subjectivities as those of small children restricted their agency and did not increase their opportunities to develop as responsible actors.

Both the Vallby and Myrmarken mealtime networks were characterized by relationships of spatio-temporal interference, which made the intent of the meals unclear and undermined the overall purpose of the interventions. These networks highlighted the power relationships between teenagers and staff. 
Spatio-temporal interference was also in play in Sandbacken, though in a different way. This was the only institution that did not try to replicate the family kitchen or family meal; its dining network instead enrolled the staff and teenagers by creating a distance from the rest of the HVB. The ambiguities present in the HVB as a totality were therefore avoided at mealtimes (cf. Dorrer et al., 2010). The guesthouse metaphor worked well in the old institutional spatial structure in which the students assumed the subjectivity of guests interacting with service staff. Contrary to the more open and visible power relationships in Vallby and Myrmarken, this was a spatial and material seduction in which the HVB's asymmetrical power relationships between staff and teenagers were hidden (Dovey, 2008). The teenagers did not see through this powerful strategy, which was seemingly more effective than the more ambiguous family metaphors enacted in the other studied institutions.

Both the teenagers' and staffs' subjectivities emerged in various manifestations in the mealtimes studied, depending on the negotiations between architectural space and other actors. The different translations in the three meal networks created various mobilization opportunities for the teenagers as regards responsibility and normality. It seemed that Sandbacken's meal translations most unanimously advanced the goal of the setting, i.e. to mobilize the teenagers as responsible and accountable. These results challenge the family metaphor in social and pedagogical practices for teenagers with SEBD.

The analysis of institutional everyday life, made through an actor-network lens gives new insights in different environments for troubled youth. ANT provides analytical tools to take the many complexities in these settings in consideration in the analysis. ANT helps to see both humans and non-humans as important actors (Callon, 1986; Latour, 2005) when creating institutions for teenagers with SEBD. 


\section{References}

Callon, M. (1986). Some elements of a sociology of translation: domestication of the scallops and the fishermen of St Breuc Bay. In J. Law (Ed.), Power, Action and Belief. A New Sociology of Knowledge (pp. 196-233). London: Routledge \& Kegan Paul.

DeLanda, M. (2006). A New Philosphy of Society: Assemblage Theory and Social Complexity. London: Bloomsbury.

Dorrer, N., McIntosh, I., Punch, S., \& Emond, R. (2010). Children and food practices in residential care: ambivalence in the 'institutional' home. Children's Geographies, 8(3), 247-259. doi: 10.1080/14733285.2010.494863

Dovey, K. (2008). Framing Places: Mediating Power in Built Form. London: Routledge.

Fenwick, T. D. (1998). Managing space, energy, and self: junior high teachers' experiences of classroom management. Teaching and Teacher Education, 14(6), 619-631. doi: http://dx.doi.org/10.1016/S0742-051X(98)00012-2

Kendrick, A. (2013). Relations, relationships and relatedness: residential child care and the family metaphor. Child \& Family Social Work, 18, 77-86.

Kohli, R., Connolly, H., \& Warman, A. (2010). Food and its meaning for asylum seekning children and young people in foster care. Children's Geographies, 8(3), 233-245. doi: 10.1080/14733285.2010.494862

Latour, B. (2005). Reassembling the social: an introduction to actor-network-theory. Oxford: University Press.

Latour, B., \& Yaneva, A. (2008). "Give me a gund and I will make all buildings move": an ANT's view on architecture. In R. Geiser (Ed.), Explorations in Architecture: Teaching, Design, Research (pp. 80-88). Basel: Birkhäuser Forlag.

Law, J. (1996). Organizing accountabilities: ontology and the mode of accounting. In R. M. Munro (Ed.), Accountability: Power,ethos and the technologies of managing. London: Thomas Business Press.

Murdoch, J. (1998). The spaces of Actor-Network Theory. Geoforum, 29(4), 357-374.

Punch, S., \& McIntosh, I. (2013). Food is a funny thing within residential care: Intergenerational relationsship and food practices in residential care. Childhood, $0(0)$, $1-15$.

Severinsson, S. (2010). Unga i normalitetens gränsland: undervisning och behandling $i$ särskilda undervisningsgrupper och hem för vård eller boende. (Doctoral thesis), Linköping University, Norrköping.

Severinsson, S., Nordh, C., \& Reimers, E. (2014). Ambiguous spaces for Troubled Youth. Home, therapeutic institution or school? Pedagogy, Culture and Society. doi: 10.1080/14681366.2014.977807

Shilling, C., \& Cousins, F. (1990). Social Use of the School Library: The Colonisation and Regulation of Educational Space. British Journal of Sociology of Education, 11(4), 411-430. doi: 10.2307/1392876

Thompson, R., Russell, L., \& Simmons, R. (2013). Space, place and social exclusion: an ethnographic study of young people outside education and employment. Journal of Youth Studies, 17(1), 63-78. doi: 10.1080/13676261.2013.793793

Winzer, M. (2005). International comparisons in EBD. In P. Clough, P. Garner, P. J.T \& F. Yuen (Eds.), Handbook of Emotional and Behavioural Difficulties. London: Sage Publications. 
Wright, A.-M. (2009). Every child matters: discourses of challenging behaviour. Pastoral Care in Education, 27(4), 279-290.

Wylie, J. (2010). Non-representational subjects? In B. Anderson \& P. Harrison (Eds.), Taking-Place: Non-Representational Theories and Geography (pp. 99-114). Farnham: Ashgate.

Youdell, D. (2006). Impossible Bodies, Impossible Selves. Exclusions and Student Subjectivities. Dordrecht: Springer. 